\title{
Estrategias didácticas Y PLAN DE Actividades PARA EL diseño CURRICULAR dEL CURSO básico DE LA ENSEÑANZA DE LA "INGENIERÍA dEL SoFTWARE" A PARTIR DEL PROYECTO SWEBOK
}

\author{
Diego Alejandro Guerrero Peña*
}

\section{Resumen}

Las instituciones de educación superior han tenido que evolucionar sus metodologías de enseñanza de la Ingeniería del Software, para gestar profesionales eficientes en el desarrollo de aplicativos informáticos. Este artículo pretende presentar una nueva didáctica y un diseño curricular de un curso de "Ingeniería del Software Básico", basado en el modelo SWEBOK de la IEEE (Guide to the software engineering body of knowledge. Swebok) y adaptado al modelo por competencias presentes en el Modelo Pedagógico del INSTITUTO TECNOLÓGICO METROPOLITANO, como resultado del proyecto de investigación HICAP-IOI del ITM.

\section{Palabras clave}

Metodología de enseñanza aprendizaje, metodología de desarrollo de software, ingeniería del software, teoría de la actividad, teoría del caos.

\footnotetext{
* Ingeniero de sistemas, especialista en gerencia de proyectos, candidato a Magíster en Ingeniería Informática de EAFIT, docente investigador del ITM en asignaturas de la ingeniería del software y relacionadas.

diegoguerrero@itm.edu.co;

dguerrer@eafit.edu.co
} 


\section{Abstract}

Higher education institutions have taken up new software engineering teaching methodologies in order to prepare professionals who are efficient in the development of informatics applications. This article aims at showing a new didactic, and a syllabus design for a course of "Basic Software Engineering", based on the SWEBOK model of IEEE (GUIDE TO THE SOFTWARE ENGINEERING BODY OF KNOWLEDGE SWEBOK), which is adapted to the model by competences which is applied in the ITM's Pedagogical Model as a result of the HICAP-IOI research project at ITM.

\section{Key Words}

Teaching Methodology, learning, software development methodology, software engineering, theory of activity, theory of chaos. 


\section{INTRODUCCIÓN}

La educación ha evolucionado al mismo ritmo que lo ha hecho el hombre. Durante el último siglo, especialmente desde los años ochenta, han surgido cambios en la educación debido a las variaciones sociales, políticas y tecnológicas. Uno de los cambios más significativos ha sido el tecnológico informático, el cual nos reta constantemente a involucrar, o por lo menos a tener en cuenta, sus avances. Entonces, nos encontramos con una variedad de elementos pasados y presentes, tales como: las corrientes pedagógicas, el avance en el software y el hardware, y las metodologías que existen para el manejo de cada uno de estos elementos, que por su sinergia llaman a la unión de todos ellos para sacar el mejor provecho en cuanto a las nuevas metodologías de enseñanza aprendizaje.

Hoy tomamos temas como la ingeniería del software y cómo enseñarla, la propuesta pedagógica de Ausubel (En POZO, 1989)1 y otros autores (COLON, 2002), (ANAYA y TRUJILLO, 2006), (VYGOTSKI, 1996) y las TIC $^{2}$ para lograr un aporte integral a la enseñanza de la ingeniería del software. Es decir, integrar estos elementos de tal manera que se logre un proceso de aprendizaje de la ingeniería del software más efectiva, donde los alumnos mejoren y proyecten esos logros en su futura labor.

En consecuencia, y teniendo en cuenta el modelo pedagógico del ITM (URREGO, 1999), se lleva a cabo el desarrollo del proyecto Herramienta informática como apoyo pedagógico a la asignatura Ingeniería del Software orientado a objetos -HICAP-IOI ( GUERRERO, 2006a) que constituye un apoyo pedagógico importante en la asignatura Ingeniería del Software Orientada a Objetos, además facilita, por un lado, la realización de exámenes automáticos que ayudan a reforzar los conocimientos de los estudiantes; $y$, por el otro, a los docentes para elaborar evaluaciones teniendo en cuenta

\footnotetext{
1 Interesa para este artículo solo La teoría del aprendizaje significativo de Ausubel, comentada por Pozo en el libro POZO, J.I. (1989).

2 Tecnologías de Información y Comunicaciones.
} 
los indicadores de logro del estudiante. Durante el desarrollo del proyecto (2005 - 2006), se evidenció la necesidad de replantear el diseño curricular de la asignatura Ingeniería del Software ISI54, en cuanto a las competencias, los indicadores de logro y la red de concepto, dando como resultado el nuevo diseño curricular para el $2007^{3}$ (GUERRERO: 2006) y la propuesta de nuevas estrategias didácticas y plan de actividades para ser implementadas en ISI54, las cuales se presentan en este artículo.

Por lo anterior, se replantea una propuesta más global y profunda del diseño curricular del curso básico de la enseñanza de la ingeniería del software, tanto en el contenido como en la metodología de enseñanza, que pretende tomar los elementos de la metodología de SWEBOK, un proyecto de la IEEE 4 (IEEE: 2004), integrados en la propuesta realizada por Raquel Anaya y John Trujillo (ANAYA, Raquel y TRUJILLO, John: 2006) así como de la experiencia de más de 12 años en docencia del autor de este artículo. La didáctica planteada surge desde la perspectiva de la práctica del desarrollo de software, atendiendo a la situación actual de las empresas de software colombianas (ANAYA: 2005) adaptado al Modelo pedagógico del ITM.

Inicialmente, se presentan los postulados pedagógicos en los cuales se basa la propuesta del diseño curricular (diseño instruccional); luego se presentan dos mapas conceptuales, uno trata sobre los elementos que componen el modelo SWEBOK y el otro, define las estrategias didácticas aplicadas a la categoría "Productos del Software" del modelo SWEBOK mediadas por las TIC, con el fin de ubicar al lector con respecto a los componentes didácticos mediados por TIC, que se deben manejar en cada una de las actividades del diseño curricular; continúa con la explicación de la didáctica

3 Es imprescindible aclarar que ISI54 es la primera asignatura, o curso inicial, que trabaja el tema de la ingeniería del software en el programa académico Ingeniería de sistemas de información del I'TM del 2007.

4 COMPUTER SOCIETY PROFESSIONAL PRACTICES COMITÉ, Disponible en www.swebok.org 
general para ser manejada en las actividades de las sesiones de clase; luego, sigue con las estrategias de aprendizaje para ser utilizadas en las actividades. Como compendio de lo anterior, se presenta el plan de actividades del diseño instruccional del Curso inicial del proceso de enseñanza de la Ingeniería del Software.

Por último, se presentan las conclusiones y la propuesta para futuros desarrollos con el fin de mejorar los cursos similares y desarrollar nuevas estrategias didácticas, utilizando elementos interactivos $\mathrm{y}$ virtuales.

\section{Postulados penagógicos}

A continuación se presentan, de manera sintetizada y como postulados, los principios pedagógicos que sustentan en gran parte, el trabajo realizado.

POSTULADO 1. La mediación efectuada por las TIC genera múltiples factores estructurales que rodean e influyen en la relación didáctica que se da entre el docente y el estudiante, y entre, éstos y el saber. La tecnología se constituye como una instancia para apoyar situaciones de gestión de clausuras explícitas o implícitas, que evolucionan en el mantenimiento constante del contrato de deberes y derechos entre quien enseña y quien aprende, acciones que se espera sirvan de ayuda para lograr una construcción más autónoma por parte del alumno (TRUJILLO y JARAMILLO: 2006, 98).

En el modelo pedagógico del ITM, el tiempo independiente es considerado fundamental para el trabajo de los estudiantes fuera de clase, por tal razón, utilizar las TIC es de vital importancia, puesto que facilitan y potencializan la aprehensión del conocimiento, a la vez que sirven como medios de apoyos para la comunicación entre los alumnos y el docente, siempre que permitan el descubrimiento individual de cada estudiante y su acercamiento al saber. Esta situación se advierte en la parte titulada "Descripción de las actividades sin acompañamiento", del diseño curricular propuesto. 
POSTULADO 2. En una siguiente construcción de correlaciones se reconocen ${ }^{5}$ las diferentes intervenciones que los estudiantes hacen con la tecnología para interactuar con el docente, sus compañeros y los contenidos, o hacer despliegue de sus propuestas ante los otros. En estos escenarios se marcan las diferencias entre la unidireccionalidad y la bidireccionalidad, la sincronía y la asincronía, la conectividad y la no conectividad a la red. Todas estas situaciones potencian procesos de apropiación, proyección, extrañamiento y reconocimiento alrededor del logro de expectativas individuales o colectivas, dentro o fuera de la intencionalidad curricular. (TRUJILLO y JARAMILLO: 2006, pp. 101-102)

Como el proyecto es desarrollado por un grupo de estudiantes, bajo la dirección del docente, se propone, entonces, exponerlo entre ellos mismos con el fin de compartir experiencias que permitan la apropiación y revisión del conocimiento adquirido por éstos, en el desarrollo del mismo, así como el adquirido por los compañeros. Esto lo pueden realizar en foros virtuales y/o presenciales con la coordinación del docente encargado.

POSTULADO 3. "Es el hombre el que debe enfrentarse a la realidad vacía; un hombre que es capaz de vivir sin ayudas, porque ya no las necesita. Un hombre que ante nada será el encargado de crear el mundo" (COLÓN: 2002, 87) ${ }^{6}$. Es el aprendiz el que debe construir sus propios conocimientos y el que es responsable de los mismos.

En la propuesta del diseño curricular o instruccional y de las estrategias de enseñanza y aprendizaje, se explicita la necesidad de permitirle al estudiante generar su propio conocimiento mediante la exploración del material bibliográfico, de las tecnologías informáticas disponibles y de las asesorías programadas por el docente. También se aclara la importancia de hacerle consciente al estudiante sobre la responsabilidad que tiene con su propio aprendizaje y con la utilización adecuada del tiempo independiente

\footnotetext{
: En la figura 1, véase el Triángulo del aprendiz, contenidos y tecnología.

6 Sólo se analiza la Teoría del caos- Superhombre de Nietzsche.
} 
para la construcción del conocimiento, asimismo, hacerle consciente que la adquisición del conocimiento es individual aunque las actividades se realicen en grupo.

POSTULADO 4. El contexto natural de ubicación de la Teoría del Caos es la Complejidad, de tal manera que sin situaciones complejas no se daría caos; por lo tanto, hablar de teoría del caos es hablar de la COMPLEJIDAD; por lo tanto, supone aceptar el desorden, la innovación y el movimiento como aspectos inherentes a cualquier situación caótica, por lo que la teoría del caos, indudablemente, se nos presenta como otro fundamento para la Teoría Social y por ende para la Teoría Educativa [...] (COLÓN: 2002, 102).

El estudiante debe enfrentar el desarrollo de un proyecto real, que dé solución a un problema existente. Esta situación le permite explorar nuevos conocimientos y buscar cada vez información que le ayude a solucionar el proyecto planteado en la asignatura (Ver diseño instruccional propuesto); también le implica trabajar en equipo y enfrentarse a diferentes situaciones de discusión, nuevas hipótesis, nuevas formas de trabajo, nuevos retos que superar, etc., que le permitirán reafirmar sus conocimientos y sus apreciaciones de los fenómenos observados.

POSTUlado 5. "La Teoría del Aprendizaje Significativo elaborada desde una posición Organicista que se centra en el aprendizaje producido por un contexto educativo, en una situación de interiorización o asimilación a través de la instrucción". (POZO: 1989, 209). De lo anterior, se extrae que el aprendizaje importante que realiza un individuo, se adquiere por la relación de los nuevos conocimientos con los conocimientos previos.

La aplicación de la teoría del aprendizaje significativo, permite al estudiante desarrollar la capacidad de relacionar los conceptos y conocimientos adquiridos con los nuevos y, poder generar con estas relaciones nuevos conocimientos. El diseño instruccional propuesto presenta una correlación en la red de conceptos que facilita al estudiante generar los conectores entre los conocimientos adquiridos para lograr un aprendizaje significativo. Igualmente, invita a que 
el docente en su didáctica les ayude a usar los conectores de una mejor manera (ver tipos de asesorías en el diseño instruccional).

POSTULADO 6. La razón como producto de interacción social ${ }^{7}$. Resaltar la coordinación de comunicaciones como valor fundamental para co-construir conocimiento. La comunicabilidad y la comprensión de eso que se comunica. La interacción social ejerce sobre los sujetos relaciones de presión y de colaboración. A través de la confrontación con otros, el sujeto analiza su propio pensamiento y toma conciencia de su modo de organización, de tal manera que enriquece el mecanismo de la razón (VYGOTSKI: 1996, y LEONTIEV: 1981).

En el diseño instruccional se propone la realización de un proyecto en grupos de estudiantes (Ver diseño instruccional), estos proyectos se deben presentar a los otros grupos de estudiantes a través de foros participativos (virtuales o no) que permitan la confrontación de las experiencias y el conocimiento adquirido; esto permite la creación de criterios sustentables de lo realizado, como también el replanteamiento de conceptos adquiridos, lográndose una afirmación del saber en el estudiante.

POSTULADO 7. Las discusiones sobre didáctica en los contextos educativos contemporáneos exigen acercamientos interpretativos a estrategias de comunicación que llevan a propuestas de diseño instruccional más flexibles. Estos, a la vez, hacen evidente una arquitectura de los aprendizajes apoyada en los contenidos que se transmiten en soportes tecnológicos móviles. (TRUJILLO y JARAMILLO: 2006)

Se propone la utilización de las nuevas tecnologías como mediadoras del aprendizaje, tales como: salas de informática, videos sobre los contenidos de la asignatura, videos sobre algunas de las sesiones de clase, celulares y otros móviles que permitan ver los videos y/o comunicarse con la red inalámbrica para las sesiones virtuales, etc.

7 Tomado de ANAYA y TRUJILLO: 2006. Principios Pedagógicos-Didácticos. En: Un modelo para la enseñanza en contexto de la Ingeniería de Software. 


\section{Estrategias didácticas}

Partiendo del proyecto SWEBOK, de las diferentes posturas dirigidas a los aprendizajes analizados y condensados en los Postulados Pedagógicos referenciados y de las apreciaciones de algunos colegas y expertos ${ }^{8}$, se definen las siguientes estrategias didácticas aplicadas a la categoría "Productos del Software", a través de un mapa conceptual, con el propósito de establecer cuáles estrategias son más directamente mediadas por las TIC, para tener en cuenta en el momento de elaborar el diseño instruccional del Curso inicial del proceso de enseñanza de la Ingeniería del Software, así como para futuros cursos (ver Figuras 1 y 2):

Figura 1. Mapa conceptual propuesto

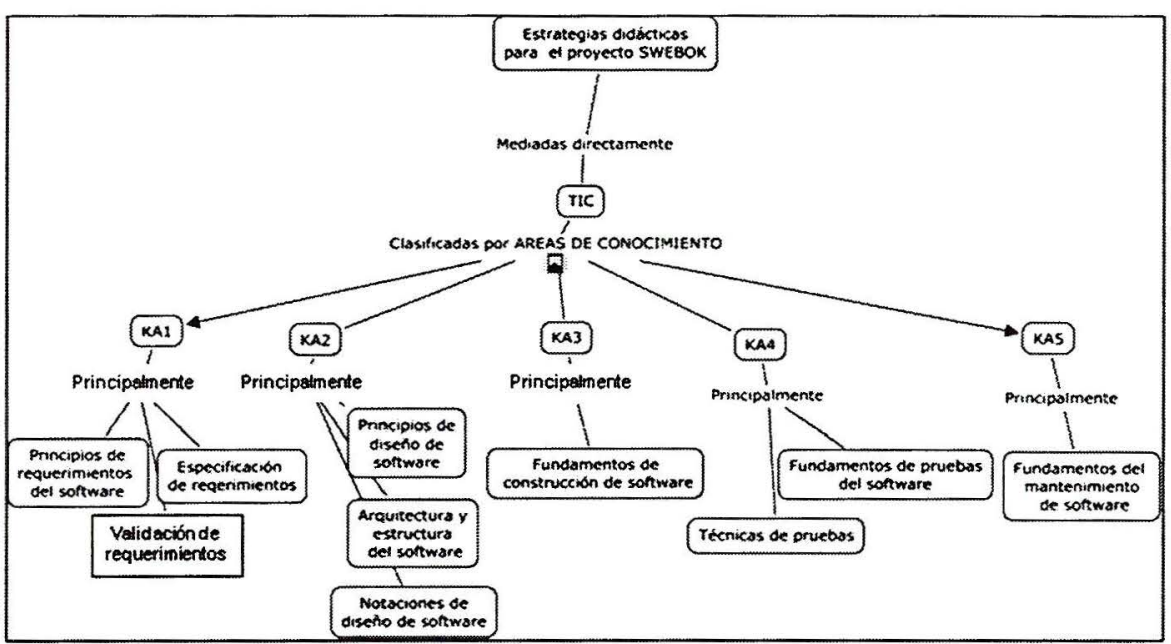

8 Se agradece a Raquel Anaya, John Trujillo, Idilia Urrego y Alejandro Villa. 
Figura 2. MAPA Conceptual de sWebok.

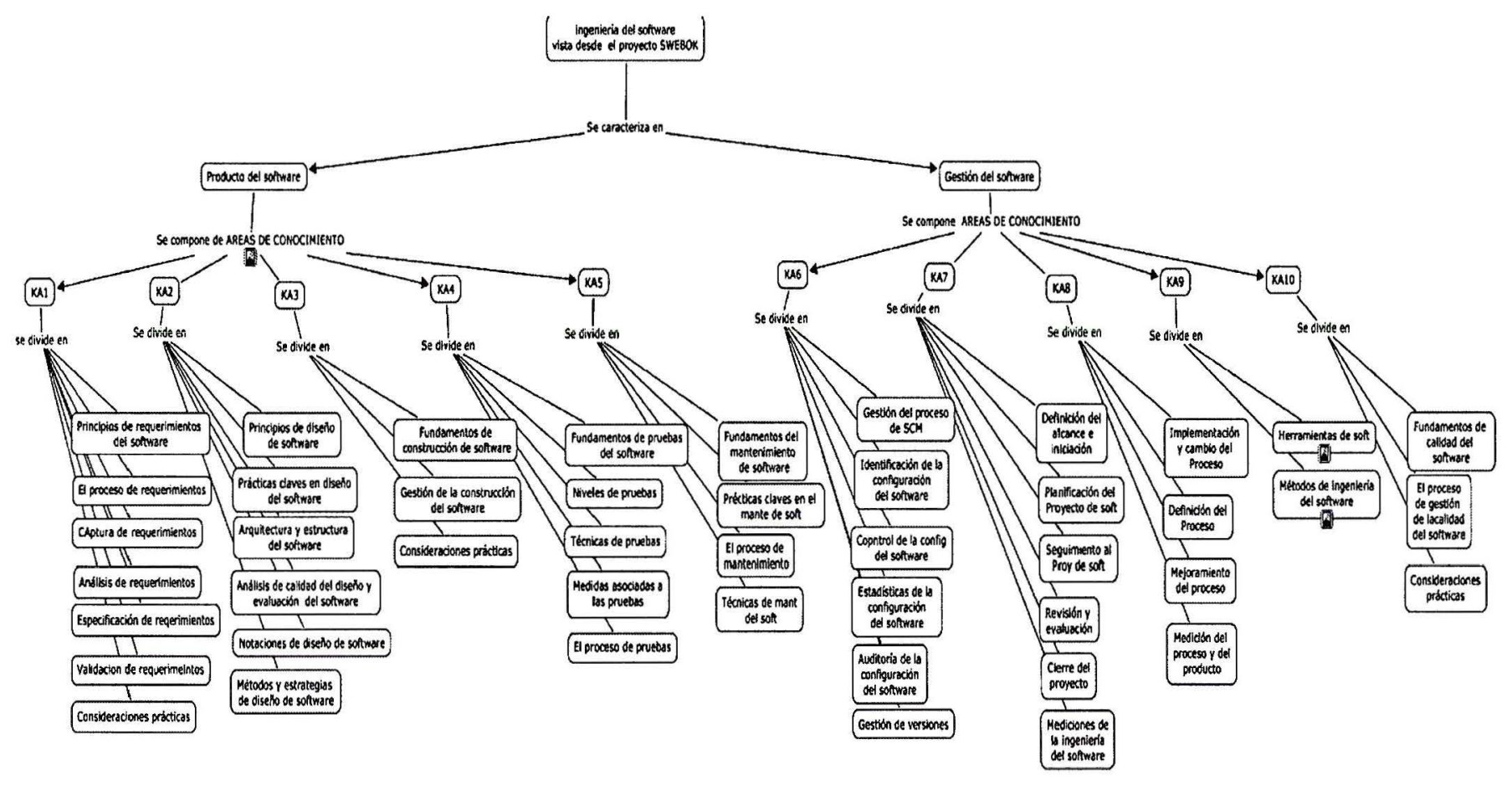




\section{Didáctica de las actividades}

Las actividades de la clase pueden fluir en espiral (Figura 3) pasando por cada uno de los estadios correspondientes. Se empieza por un proceso de documentación, en el cual el alumno obtiene por parte del docente y de sí mismo la documentación necesaria para continuar con el proceso de aprendizaje. Luego se va a un estadio de inducción donde se hace una introducción formal al tema, se aclara el tema como tal y se motiva al estudiante a seguir y desarrollar actividades definidas por el docente. En este punto el alumno hace deducciones según el caso, es decir, elabora su proyecto (se explicará más adelante) utilizando las técnicas y modelos que considere más adecuados. Se continúa con el proceso de abducción en donde plantea discusiones y nuevas soluciones al docente y a sus compañeros, para pasar nuevamente por la documentación y continuar el recorrido por el espiral. A medida que se sale de la espiral, se presenta mayor conocimiento y mayor grado de complejidad.

Figura 3. Proceso en espiral

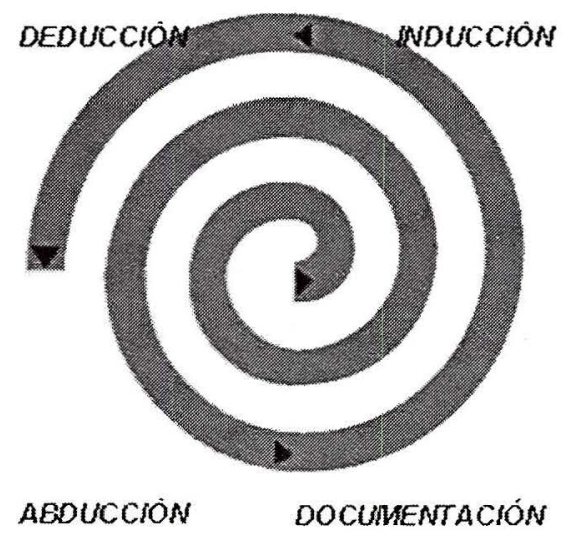




\section{ACTIUIDADES Y ESTRATEGIAS DE APRENDIZANE}

\subsection{Indicación metodológica}

Retomando el modelo de SWEBOK, se desarrollarán las actividades y estrategias de aprendizaje y enseñanza de la ingeniería del software en el contexto de la carrera Ingeniería de Sistemas, aplicando el análisis propuesto en el presente trabajo.

$\mathrm{Al}$ iniciar la asignatura, el docente explica el desarrollo del curso, el programa académico, la metodología de trabajo (didáctica de las actividades), fechas de evaluación y entregas de trabajos ${ }^{9}$.

\subsubsection{Medios a mitilzar}

- Exposición magistral

- Foros, talleres y correos virtuales mediante el aplicativo informático de apoyo (HICAP IOI)

- Talleres de aplicación inmediata entre el tema expuesto magistralmente y su posible utilización en el entorno socio - económico empresarial y en la actividad profesional en general

- Talleres de observación - aplicación en la empresa y la universidad, cotejando la relación teórica práctica entre la conceptualización y la aplicación

- Talleres de investigación para que el alumno indague, busque y obtenga respuesta a cuestionamientos previamente planteados

- Discusiones guiadas

- Horas definidas extra clase para asesorías grupales e individuales

- Foros presenciales

- Exposiciones de los estudiantes, individuales y en grupos, sobre temas inherentes al proceso de desarrollo de los sistemas de información en la etapa de análisis de requisitos

$9 \quad$ Se explican en el tiempo independiente. 
- Software educativo instalado en las salas de informática (HICAP IOI)

Discos compactos-CD- con:

- Aplicativos para el desarrollo de sistemas de información (software libre o comercial-académico )

- Ejemplos de sistemas de información desarrollados

- Documentos principales: Diseño Curricular y Guías de Trabajo independiente

- Libros técnico digitales

- Formatos para el desarrollo de proyectos utilizando varias metodologías

- Bibliografía básica

- Página WEB (www.itm.edu.co) donde se encuentra toda la información de la asignatura, el aplicativo informático (HICAPIOI) y las herramientas virtuales

Discos compactos-CD- con :

- Software con la herramienta de apoyo informático en el desarrollo de sistemas de información, con talleres, foros etc.

- Videos sobre los conceptos a manejar en la asignatura, realizados por los docentes

\subsubsection{Sesiones de clase}

El proceso de enseñanza y aprendizaje se cumple en este curso mediante la articulación, presentación, explicación y desarrollo del tema con la exposición magistral, para dar un referente temático y conceptual de todos y cada uno de los temas, pero este método se complementa y amplía con la permanente confrontación práctica a través de talleres, lecturas, trabajos prácticos en clase, revisión y análisis de videos e investigación de sistemas informáticos ya desarrollados en empresas, que lleven al alumno a la racionalización del concepto con la práctica aplicada, que le genere cuestionamientos, preguntas e inquietudes sobre cada uno de los temas que se desarrollen en clase, que se investiguen 
u observen en el exterior para hacer el cotejamiento entre el entorno y aquello que el proceso de enseñanza y aprendizaje aporta.

A partir de la presentación magistral de los temas por parte del profesor, de elaboración de talleres y realización de exposiciones por parte de los estudiantes se realiza la confrontación de lo aplicado por éstos, según el nivel de conocimiento que se esté adquiriendo. El docente brinda un espacio de asesoría para dar explicaciones individuales y a los grupos de trabajo, con el fin de inducirlos inicialmente en el área de conocimiento que requieren dominar.

El docente dejará en la página web de la asignatura el video de la clase, si lo considera necesario. Éste podrá ser visto desde dispositivos móviles o en las salas de informática o en la biblioteca; al igual que desde cualquier sitio con conexión a Internet.

Antes de cada clase los alumnos deben de estudiar la documentación definida y programada por el docente, realizar los talleres y trabajos expuestos en los CD, o en la página web, y detallados en las Guías de Trabajo independiente ${ }^{10}$.

\subsubsection{Tipos te clases}

El Profesor utilizará, básicamente, tres tipos de clases:

\section{Clase presencial magistral}

El profesor induce a la aprehensión de los conceptos teóricos y los fundamentos básicos de los respectivos temas, con el propósito de aclarar dudas del estudiante, para luego presentar talleres teórico-prácticos que le permiten al estudiante la confrontación de lo enseñado con lo aprendido.

Para ello, el profesor se apoya en varios ejemplos de sistemas de información desarrollados que se entregan a los estudiantes en medios magnéticos y en la página $\mathrm{WEB}$, con el fin de presentar los conceptos de manera más práctica.

10 Ver las guías de trabajo independiente de la asignatura Ingeniería del Software Orientado a Objetos 2007 (GUERRERO: 2006b) éstas son similares a las que se deben desarrollar como trabajos futuros para complementar el desarrollo de esta propuesta. 
En este tipo de clase también se realizan las evaluaciones a los estudiantes.

\section{Clase presencial práctica}

El profesor asesora a los estudiantes en el desarrollo de un sistema de información ${ }^{11}$, tanto individual como grupal, así mismo, dará asesoría sobre los conceptos trabajados.

\section{Clase no presencial}

Son clases donde el docente interactúa con los estudiantes a través de medios computacionales (foros virtuales, video conferencia, audio conferencia, chats y video chats entre otros) durante los horarios establecidos para la asignatura; de esta manera los estudiantes pueden solicitar asesoría directa sobre los problemas que los aquejan en el desarrollo de su sistema de información, viendo de manera directa las dificultades que se les presenta con el aplicativo que se está desarrollando (problemas con el lenguaje de programación, manejador de bases de datos, CASE etc.).

\subsubsection{Astasorias}

El docente tiene tres tipos de asesorías, la primera forma se realiza en la segunda mitad de cada clase presencial práctica, en donde brinda ayuda a sus alumnos de forma grupal e individual; la segunda forma es extra clase (tiempo independiente), es decir en los horarios definidos por el docente para asesorías, las cuales pueden por correo electrónico. La tercera forma es por medio de una herramienta informática (HICAP-IOI a futuro) la cual permite una interacción con el docente y con los compañeros mediante foros, consultas, chats, video chats, etc.

La herramienta informática se debe utilizar en todos los cursos; sin embargo, habrá algunos que requieren de mayor presencialidad por parte del docente (Figura 1) donde se exponen los cursos que

11 Se explican en el tiempo independiente. 
pueden ser dictados con un acompañamiento en mayor uso de virtualidad.

Tanto los foros virtuales como los presenciales permiten a los estudiantes discutir sobre los proyectos de sus compañeros. Estos foros son dirigidos por el docente.

\subsubsection{Tienpo independistre}

Durante el tiempo independiente ${ }^{12}$ del curso (128 horas), cuatro horas semanales, durante 16 semanas, el estudiante debe realizar: investigación y consulta de los conceptos de la asignatura, participar en las asesorías presenciales y virtuales y realizar un proyecto de desarrollo de un sistema de información en sus etapas de "Análisis y Diseño" las cuales culminará con la programación del sistema de información.

Antes de cada clase los alumnos deben estudiar la documentación definida y programada por el docente, realizar los talleres y trabajos expuestos en los CD, o en la página WEB, y detallados en las Guías de Trabajo Independiente (GUERRERO: 2006b).

El proyecto de desarrollo del sistema de información es realizado por grupos compuestos de tres a cinco estudiantes, quienes deben investigar en el medio el tipo de empresa a la cual le van a desarrollar el software, éste debe cumplir con los requisitos expuestos por el profesor (proceso de inducción) y por la metodología de desarrollo seleccionada. El proyecto que se realizará va incrementando su complejidad a medida que se adquiere mayor conocimiento y se desarrollan las competencias pertinentes. Continúa con el proceso de deducción que puede ser individual o grupal, es decir, el alumno compara sus deducciones con las de sus compañeros de trabajo del proyecto para reafirmar

12 El tiempo independiente aparece establecido en el Modelo Pedagógico del ITM como el tiempo que el estudiante debe dedicar, fuera de clase, para adquirir las competencias de la asignatura, éste aparece en el diseño instruccional y depende de cada asignatura, aunque en general por cada hora de clase el estudiante debe dedicar dos horas de tiempo independiente. 
o corregir los nuevos conceptos adquiridos y continuar aplicándolos al proyecto en desarrollo. Esto lo puede hacer en reuniones en el aula de clase o en reuniones virtuales mediante videoconferencia, audioconferencia, chats o video chats.

Durante el desarrollo del proyecto deben entregar tres trabajos, explicados en las Guías de Trabajo Independiente ${ }^{13}$. Este proyecto debe ser ingresado al aplicativo HICAP IOI para ser revisado por el docente (GUERRERO: 2006b). Durante las revisiones parciales del proyecto (asesorías) por parte del docente, se realiza un proceso de abducción donde el estudiante sustenta sus posturas críticas con respecto a los métodos y herramientas utilizadas en el proyecto.

\subsubsection{Sistema de evaluación}

La evaluación se divide en dos porcentajes: un 50\% se evalúa a través de exámenes, participación en clase, formación profesional y trabajo en equipo; el otro $50 \%$ corresponde a la evaluación de un proyecto de desarrollo de un sistema informático, donde se evalúa el logro de la competencia a través de la creación o aplicación de soluciones prácticas.

Este último se evalúa con la entrega de tres informes, así:

$1^{\circ}$ Informe del "preanálisis" y parte inicial del "análisis"

$2^{\circ}$ Informe de la entrega del resto del "análisis" y parte inicial del "diseño"

$3^{\circ}$ Informe de la entrega de la parte final del "diseño" y el aplicativo funcionando

El sistema de evaluación se extiende a un permanente seguimiento, se parcela la materia por sesiones de clase, se establecen los talleres, exámenes rápidos (quices), talleres de ejecución en

13 Ver las guías de trabajo independiente de la asignatura Ingeniería del Software orientado a objetos 2007 (GUERRERO: 2006b) éstas son similares a las que se deben de desarrollar como trabajos futuros, para complementar el desarrollo de esta propuesta. 
clase, talleres de seguimiento realizados en casa, investigación de sistemas de información en empresas y participación dinámica en clase.

Cada semana se dictan dos clases de dos horas cada una, durante 16 semanas, por ello se establece el siguiente cuadro de evaluación:

\begin{tabular}{|c|c|c|}
\hline INDICADOR DE LOGRO & PORCENTAJE & FECHA \\
\hline $\begin{array}{l}\text { Primer informe } \\
\text { (preanálisis - análisis) }\end{array}$ & $10 \%$ & Tercera semana \\
\hline $\begin{array}{l}\text { Segundo informe } \\
\text { (análisis - diseño) }\end{array}$ & $20 \%$ & Octava semana \\
\hline Examen parcial 1 & $20 \%$ & Novena semana \\
\hline $\begin{array}{l}\text { Tercer informe } \\
\text { (Diseño - implementación) }\end{array}$ & $20 \%$ & $\begin{array}{l}\text { Decimocuarta } \\
\text { semana }\end{array}$ \\
\hline $\begin{array}{l}\text { Seguimiento (Exámenes cortos, } \\
\text { participación, entrega de tareas) }\end{array}$ & $10 \%$ & $\begin{array}{l}\text { Hasta la decimo- } \\
\text { quinta semana }\end{array}$ \\
\hline Examen parcial 2 & $20 \%$ & $\begin{array}{l}\text { Decimoquinta } \\
\text { semana }\end{array}$ \\
\hline
\end{tabular}

Para lograr la competencia (ver capítulo 6.1. Desarrollo de diseño curricular) el estudiante debe alcanzar todos los indicadores de logro; para ello el docente debe ponderarlos y correlacionarlos.

La evaluación de los informes depende de la calificación obtenido en el informe anterior, ya que el proyecto se compone de los 3 informes. Un estudiante no puede ganar el informe 2 sin haber ganado (alcanzar el indicador de logro) del informe 1, esto se aplica para el informe 3 .

\subsubsection{Aplicación de la cvaluación}

El docente verifica mediante exámenes y evaluación de los proyectos el avance de los alumnos y realiza las correcciones pertinentes. Para lo anterior, la herramienta informática (HICAP-IOI) 
le facilitará la creación de la base de datos de preguntas, la creación de cuestionarios de preguntas aleatorias por red de conceptos, por conceptos o en general por todos los conceptos de la asignatura (GUERRERO: 2006a), además, le permitirá la evaluación de cada uno de sus estudiantes revisando los indicadores de logro y las competencias en las cuales tiene falencias ${ }^{14}$, el docente puede realizar recuperaciones creando exámenes según los logros no alcanzados, es decir, puede crear distintos tipos de exámenes para los estudiantes según las deficiencias de cada uno.

La validación de los proyectos y de las competencias debe ser realizada por un grupo de docentes, cada uno evalúa su especialidad, a través de una exposición y sustentación realizada por los alumnos.

Los estudiantes tienen un tiempo límite de entrega de los trabajos y de realización de las evaluaciones, el alumno debe solicitar la realización de sus evaluaciones antes de las fechas estipuladas, para poder pasar al siguiente nivel.

El proceso de aprendizaje es en espiral, es decir, el proceso se repite a través de las sesiones de clase, en donde se incrementa el conocimiento, el grado de complejidad y la robustez de los proyectos.

El siguiente capítulo expone los elementos pedagógicos para trabajar a través del plan de actividades del diseño curricular (instruccional) de un curso básico de Ingeniería del Software, incluye sólo los principales ítems que componen una asignatura ${ }^{15}$.

14 En el aplicativo HICAP IOI encuentra el manejo de cada uno de los ítems mencionados. Este aplicativo se encuentra en funcionamiento desde el 2006-1 en las salas de informática del ITM. Se espera una segunda versión como página web para enero del 2008.

15 El plan de actividades propuesto se basa en el curso "Ingeniería de Software ISI54" del programa académico Ingeniería de Sistemas de Información del ITM. (Programa Académico Ingenieria de Sistemas de Información del ITM 2007, 2007). 


\section{Plan de actividades del diseño curricular}

El presente plan de actividades del diseño curricular pretende presentar una propuesta sobre cómo se puede enseñar "la Ingeniería del Software", utilizando el modelo SWEBOK, de una forma práctica y sencilla para un nivel educativo básico profesional, equivalente a un cuarto nivel de la carrera de Ingeniería de Sistemas; comenzando por el curso inicial. Aquí encontrarán los principales elementos para llevarlo a cabo.

\subsection{Desarrollo del diseño curricular}

\begin{tabular}{|c|c|c|}
\hline COMPETENCIAS & RED DE CONCEPTOS & INDICADORES DE LOGRO \\
\hline $\begin{array}{l}\text { Desarrollar e implementar } \\
\text { sistemas informáticos } \\
\text { utilizando herramientas } \\
\text { informáticas que manejen } \\
\text { diferentes metodologías ge- } \\
\text { nerales de análisis y diseño } \\
\text { de última generación }\end{array}$ & $\begin{array}{l}\text { Conceptualización básica } \\
\text { de los sistemas } \\
\text { de información. } \\
\text { - Sistema de información } \\
\text { y sus componentes } \\
\text { - Definición de Sistema } \\
\text { - Definición de Sistema } \\
\text { de Información } \\
\text { Introducción a la } \\
\text { Ingeniería del Software: } \\
\text { - Definición de Ingeniería } \\
\text { de Software } \\
\text { - Historia } \\
\text { - Características } \\
\text { - Crisis del software } \\
\text { - El software como } \\
\text { producto. } \\
\text { - El software como } \\
\text { proceso. }\end{array}$ & $\begin{array}{l}\text { - En el contexto de un } \\
\text { sistema de información } \\
\text { de una organización, } \\
\text { propone los modelos y } \\
\text { metodologías adecuados } \\
\text { para el desarrollo de } \\
\text { un software que dé } \\
\text { solución a un problema } \\
\text { específico. } \\
\text { - Formula y evalúa la fac- } \\
\text { tibilidad de un proyecto } \\
\text { específico de desarrollo } \\
\text { de software. } \\
\text { Realiza el desarrollo } \\
\text { completo de un apli- } \\
\text { cativo software en la } \\
\text { solución de un problema } \\
\text { específico de un proceso } \\
\text { productivo. }\end{array}$ \\
\hline
\end{tabular}




\begin{tabular}{|c|c|c|}
\hline COMPETENCIAS & RED DE CONCEPTOS & INDICADORES DE LOGRO \\
\hline & $\begin{array}{l}\text { - Modelos y metodologías } \\
\text { de desarrollo de } \\
\text { software } \\
\text { Formulación y evaluación } \\
\text { básicas de proyectos de } \\
\text { desarrollo de software. } \\
\text { Ejecución de un proyecto } \\
\text { de desarrollo de software } \\
\text { - Etapa de análisis de } \\
\text { requerimientos: } \\
\text { Principios y conceptos de } \\
\text { análisis. } \\
\text { - Construcción de } \\
\text { modelos de información } \\
\text { - Principios de la } \\
\text { especificación de los } \\
\text { requisitos del software. } \\
\text { - Etapa de Diseño de } \\
\text { software: } \\
\text { - Principios y Conceptos } \\
\text { del Diseño } \\
\text { - El lenguaje de Mode- } \\
\text { lado Unificado (UML) } \\
\text { para el desarrollo de la } \\
\text { etapa de diseño } \\
\text { - Diseño de pantallas } \\
\text { - Diseño de bases de } \\
\text { datos }\end{array}$ & $\begin{array}{l}\text { Realiza la etapa de aná- } \\
\text { lisis de requerimientos } \\
\text { en el desarrollo en un } \\
\text { aplicativo específico, } \\
\text { utilizando una herra- } \\
\text { mienta informática de } \\
\text { desarrollo de software } \\
\text { de última generación. } \\
\text { - Realiza el desarrollo } \\
\text { completo de un apli- } \\
\text { cativo software en la } \\
\text { solución de un problema } \\
\text { específico de un proceso } \\
\text { productivo. } \\
\text { Realiza la etapa de } \\
\text { diseño de software en } \\
\text { el desarrollo en un } \\
\text { aplicativo específico, } \\
\text { utilizando una herra- } \\
\text { mienta informática de } \\
\text { desarrollo de software } \\
\text { de última generación. } \\
\text { - Realiza el desarrollo } \\
\text { completo de un apli- } \\
\text { cativo software en la } \\
\text { solución de un problema } \\
\text { específico de un proceso } \\
\text { productivo. }\end{array}$ \\
\hline
\end{tabular}




\begin{tabular}{|c|c|c|c|c|c|c|c|}
\hline $\begin{array}{l}\text { SITUACIONES DE } \\
\text { APRENDIZAJE } \\
\text { CONCEPTOS NUEVOS A } \\
\text { TRABAJAR EN } \\
\text { LA SESION }\end{array}$ & COMPETENCIAS & ObJetivo & $\begin{array}{l}\text { ACTIVIDADES DURANTE LA } \\
\text { CLASE }\end{array}$ & $\begin{array}{l}\text { DESCRIPCIÓN DE } \\
\text { LAS ACTIVIDADES } \\
\text { ACADÉMICAS SIN } \\
\text { ACOMPAÑAMIENTO }\end{array}$ & $\begin{array}{l}\text { INDICADORES DE } \\
\text { LOGRO }\end{array}$ & $\begin{array}{l}\text { CONTENIDOS, } \\
\text { MATERIALES } \\
\text { Y RECURSOS } \\
\text { (DISCRIMINADOS } \\
\text { EN DETALLE) } \\
\text { RECURSOS }\end{array}$ & $\begin{array}{c}\text { No. SESIÓN } \\
\text { (HORAS TP/TI) } \\
\text { TP TIEMPO } \\
\text { PRESENCIAL } \\
\text { TI TIEMPO } \\
\text { INDEPENDIENTE }\end{array}$ \\
\hline $\begin{array}{l}\text { Conceptualiza- } \\
\text { ción básica de } \\
\text { los sistemas de } \\
\text { información. } \\
\text { - Sistema de } \\
\text { Información y sus } \\
\text { componentes } \\
\text { - Definición de } \\
\text { Sistema } \\
\text { - Definición de } \\
\text { Sistema de } \\
\text { Información } \\
\text { Introducción a } \\
\text { la Ingenieria del } \\
\text { Software: } \\
\text { - Definición de } \\
\text { Ingeniería de } \\
\text { Software } \\
\text { - Historia } \\
\text { - Características } \\
\text { - Crisis del software } \\
\text { - El software como } \\
\text { producto. } \\
\text { - El software como } \\
\text { proceso. } \\
\text { - Modelos y metodo- } \\
\text { logías de Desarrollo } \\
\text { de software } \\
\text { Formulación y } \\
\text { evaluación básicas } \\
\text { de proyectos de de- } \\
\text { sarrollo de software }\end{array}$ & $\begin{array}{l}\text { Conocer } \\
\text { y saber } \\
\text { manejar los } \\
\text { principios } \\
\text { básicos del } \\
\text { modelado } \\
\text { orientado a } \\
\text { objetos. }\end{array}$ & $\begin{array}{l}\text { Conocer } \\
\text { todos los } \\
\text { aspectos } \\
\text { que rodean } \\
\text { el desa- } \\
\text { rrollo del } \\
\text { software. } \\
\text { Conocer } \\
\text { cómo se } \\
\text { gestiona un } \\
\text { proyecto de } \\
\text { desarrollo } \\
\text { de software }\end{array}$ & $\begin{array}{l}\text { Exponer sobre los } \\
\text { modelos de desarrollo } \\
\text { de software por } \\
\text { grupos de máximo tres } \\
\text { estudiantes. } \\
\text { Realizar asesorías } \\
\text { sobre el preanálisis } \\
\text { del proyecto planteado } \\
\text { por los estudiantes } \\
\text { (en grupo de } 3 \text { a } 5 \\
\text { estudiantes). } \\
\text { Realizar actividades } \\
\text { lúdicas con el fin de } \\
\text { que los estudiantes } \\
\text { reconozcan el software } \\
\text { como producto y como } \\
\text { proceso. } \\
\text { Asesoría virtual (Chat) } \\
\text { sobre la realización } \\
\text { de la formulación y } \\
\text { evaluación del proyecto } \\
\text { de software a ser } \\
\text { desarrollado. } \\
\text { Realización de quiz, } \\
\text { utilizando HICAP IOI } \\
\text { Clase presencial para } \\
\text { evaluación }\end{array}$ & $\begin{array}{l}\text { Consultar sobre } \\
\text { el papel de los } \\
\text { sistemas de in- } \\
\text { formación en las } \\
\text { organizaciones. } \\
\text { Leer los } \\
\text { conceptos de la } \\
\text { arquitectura } \\
\text { cliente servidor. } \\
\text { Leer primeros } \\
2 \text { capítulos del } \\
\text { Libro: "Elemen- } \\
\text { tos básicos de } \\
\text { Ingeniería del } \\
\text { Software" (GUE- } \\
\text { RRERO, 2007). } \\
\text { Lectura de los } \\
\text { capítulos 1 y } 2 \\
\text { en el libro de } \\
\text { "Ingeniería del } \\
\text { Software" (PRESS- } \\
\text { MAN, 2002). } \\
\text { Leer "Guía } \\
\text { de Trabajo } \\
\text { independiente } \\
\text { No 1". } \\
\text { Lectura del } \\
\text { documento } \\
\text { "Programación de } \\
\text { Scripts". }\end{array}$ & $\begin{array}{l}\text { - En el contexto } \\
\text { de un sistema de } \\
\text { información de } \\
\text { una organiza- } \\
\text { ción, propone } \\
\text { los modelos y } \\
\text { metodologías } \\
\text { adecuados para } \\
\text { el desarrollo } \\
\text { de un software } \\
\text { que dé solución } \\
\text { a un problema } \\
\text { específico } \\
\text { - Formula y } \\
\text { evalúa la } \\
\text { factibilidad de } \\
\text { un proyecto } \\
\text { especíico de } \\
\text { desarrollo de } \\
\text { software } \\
\text { - Quiz de } \\
\text { verificación de } \\
\text { los conceptos( } \\
\text { parte del } 10 \% \text { de } \\
\text { seguimiento) } \\
\text { - Evaluación del } \\
\text { anteproyecto } \\
\text { (parte del } \\
\text { primer informe) }\end{array}$ & $\begin{array}{l}\text { Video Beam } \\
\text { y computador } \\
\text { CD 's del } \\
\text { curso Videos } \\
\text { de los } \\
\text { conceptos } \\
\text { del curso, } \\
\text { los ejemplos } \\
\text { de sistemas } \\
\text { informáticos } \\
\text { y libros } \\
\text { digitales. } \\
\text { Página } \\
\text { WEB de la } \\
\text { asignatura. } \\
\text { Montaje } \\
\text { del mapa } \\
\text { conceptual } \\
\text { con los } \\
\text { conceptos } \\
\text { principales } \\
\text { seleccionados } \\
\text { del texto } \\
\text { leído. } \\
\text { http://www. } \\
\text { educar. } \\
\text { org/articulos/ } \\
\text { usodemapas. } \\
\text { asp }\end{array}$ & $\begin{array}{c}1-4 \\
(16 / 32)\end{array}$ \\
\hline
\end{tabular}




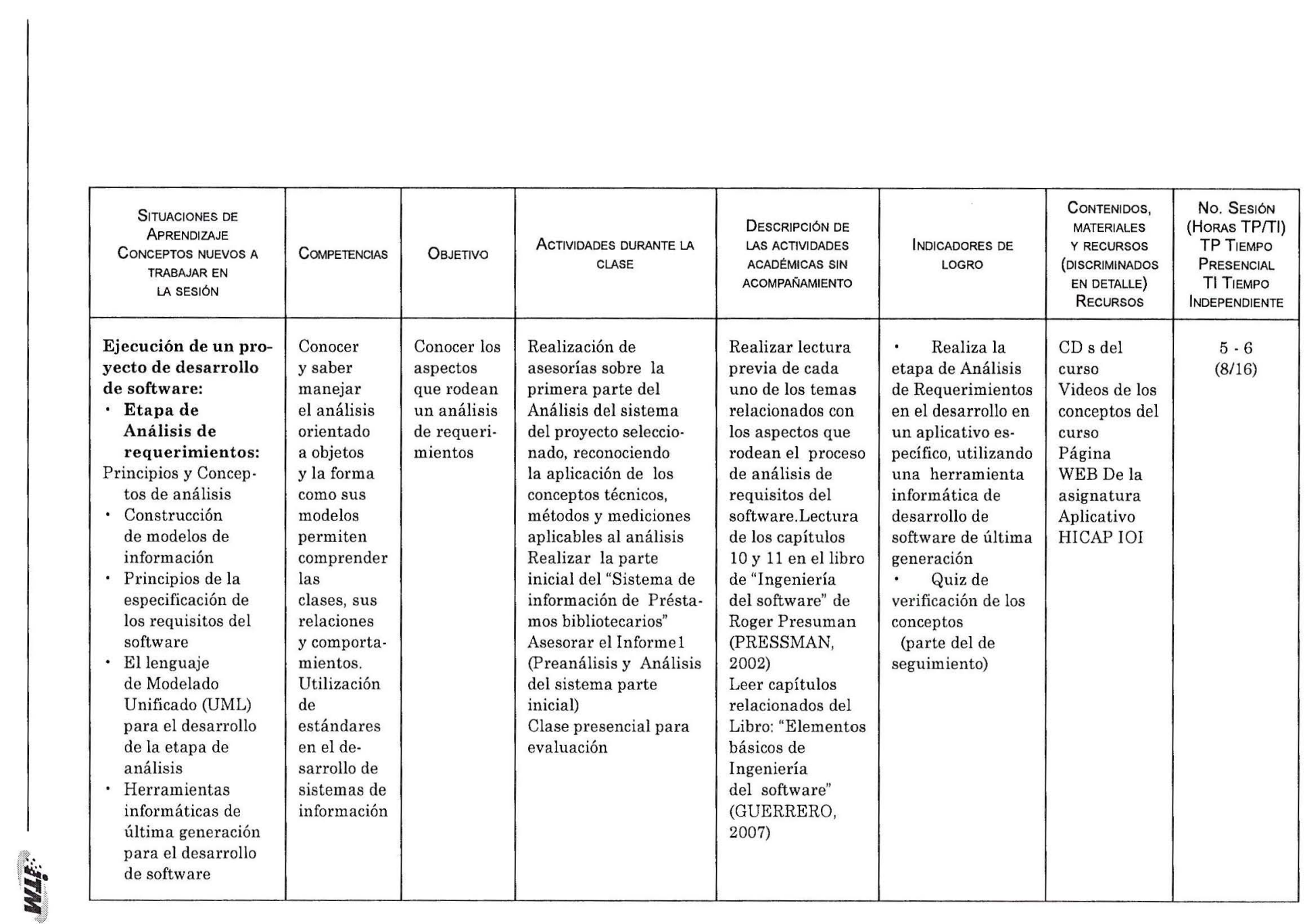




\begin{tabular}{|c|c|c|c|c|c|c|c|}
\hline $\begin{array}{l}\text { SITUACIONES DE } \\
\text { APRENDIZAJE } \\
\text { CONCEPTOS NUEVOS A } \\
\text { TRABAJAR EN } \\
\text { LA SESIÓN }\end{array}$ & COMPETENCIAS & OBJETIVO & $\begin{array}{l}\text { ACTIVIDADES DURANTE LA } \\
\text { CLASE }\end{array}$ & $\begin{array}{l}\text { DESCRIPCIÓN DE } \\
\text { LAS ACTIVIDADES } \\
\text { ACADÉMICAS SIN } \\
\text { ACOMPANAAMIENTO }\end{array}$ & $\begin{array}{l}\text { INDICADORES DE } \\
\text { LOGRO }\end{array}$ & $\begin{array}{l}\text { CONTENIDOS, } \\
\text { MATERIALES } \\
\text { Y RECURSOS } \\
\text { (DISCRIMINADOS } \\
\text { EN DETALLE) } \\
\text { RECURSOS }\end{array}$ & $\begin{array}{c}\text { No. SESIÓN } \\
\text { (HORAS TP/TI) } \\
\text { TP TIEMPO } \\
\text { PRESENCIAL } \\
\text { TI TIEMPO } \\
\text { INDEPENDIENTE }\end{array}$ \\
\hline $\begin{array}{l}\text { Ejecución de } \\
\text { un proyecto de } \\
\text { desarrollo de } \\
\text { software: } \\
\text { - El lenguaje de } \\
\text { Modelado Unificado } \\
\text { (UML) para el } \\
\text { desarrollo de la } \\
\text { etapa de análisis } \\
\text { - Herramientas } \\
\text { informáticas de } \\
\text { última generación } \\
\text { para el desarrollo } \\
\text { de software }\end{array}$ & $\begin{array}{l}\text { Conocer } \\
\text { y saber } \\
\text { manejar } \\
\text { los elemen- } \\
\text { tos de un } \\
\text { modelo de } \\
\text { análisis } \\
\text { orientado a } \\
\text { objetos, con } \\
\text { respecto } \\
\text { a los } \\
\text { diagramas } \\
\text { de casos de } \\
\text { uso. } \\
\text { Utilización } \\
\text { de } \\
\text { estándares } \\
\text { en el de- } \\
\text { sarrollo de } \\
\text { sistemas de } \\
\text { información. }\end{array}$ & $\begin{array}{l}\text { Reco- } \\
\text { nocer el } \\
\text { análisis del } \\
\text { dominio, } \\
\text { los com- } \\
\text { ponentes } \\
\text { genéricos } \\
\text { del modelo } \\
\text { de AOO, y } \\
\text { el Proceso } \\
\text { de AOO }\end{array}$ & $\begin{array}{l}\text { Llevar a cabo } \\
\text { actividades grupales } \\
\text { para que los estu- } \\
\text { diantes identifiquen } \\
\text { las diferentes } \\
\text { metodologías de AOO, } \\
\text { pero sobre todo, reco- } \\
\text { nocer como expresa } \\
\text { el análisis mediante } \\
\text { UML con respecto a } \\
\text { los diagramas de casos } \\
\text { de uso. } \\
\text { Exponer el aplicativo } \\
\text { "Sistemas de présta- } \\
\text { mos bibliotecario". } \\
\text { Utilizar los trabajos } \\
\text { desarrollados por los } \\
\text { otros compañeros para } \\
\text { ratificar conceptos. } \\
\text { Clase presencial para } \\
\text { evaluación. } \\
\text { Asesoría al desarrollo } \\
\text { del informe } 2 \text { (Análisis } \\
\text { del sistema y Diseño } \\
\text { Parte inicial). }\end{array}$ & $\begin{array}{l}\text { Exploración del } \\
\text { libro: } \\
\text { UML y patrones } \\
\text { introducción al } \\
\text { análisis y diseño } \\
\text { orientado a ob- } \\
\text { jetos (LARMAN, } \\
\text { 1999). Realizar } \\
\text { las preguntas que } \\
\text { aparecen al final } \\
\text { de los capítulos. } \\
\text { Leer"Guía de } \\
\text { Trabajo indepen- } \\
\text { diente Na 2" } \\
\text { Comenzar a rea- } \\
\text { lizar el Informe } \\
\text { del Análisis del } \\
\text { sistema bajo la } \\
\text { metodología. } \\
\text { Análisis orientado } \\
\text { a objetos del } \\
\text { proyecto a desa- } \\
\text { rrollara en grupos } \\
\text { de estudiantes. } \\
\text { Realizaciónde } \\
\text { foro virtual } \\
\text { para revisión } \\
\text { de los conceptos } \\
\text { aprendidos. }\end{array}$ & $\begin{array}{l}\text { Realiza } \\
\text { la etapa de } \\
\text { Análisis de } \\
\text { Requerimientos } \\
\text { en el desarrollo } \\
\text { en un aplica- } \\
\text { tivo específico, } \\
\text { utilizando una } \\
\text { herramienta } \\
\text { informática } \\
\text { de desarrollo } \\
\text { de software } \\
\text { de última } \\
\text { generación } \\
\text { Evaluación } \\
\text { del } 1^{\circ} \text { informe } \\
\text { (Preanálisis y } \\
\text { análisis) }\end{array}$ & $\begin{array}{l}\text { Aula de clase } \\
\text { Biblioteca. } \\
\text { CD s del } \\
\text { curso. } \\
\text { Videos de } \\
\text { los conceptos } \\
\text { del curso, } \\
\text { los ejemplos } \\
\text { de sistemas } \\
\text { informáticos } \\
\text { y libros } \\
\text { digitales. } \\
\text { Página } \\
\text { WEB de la } \\
\text { asignatura. } \\
\text { Página: } \\
\text { www.software- } \\
\text { engin.com } \\
\text { Aplicativo } \\
\text { HICAP IOI }\end{array}$ & $\begin{array}{c}7-9 \\
(6 / 12)\end{array}$ \\
\hline
\end{tabular}




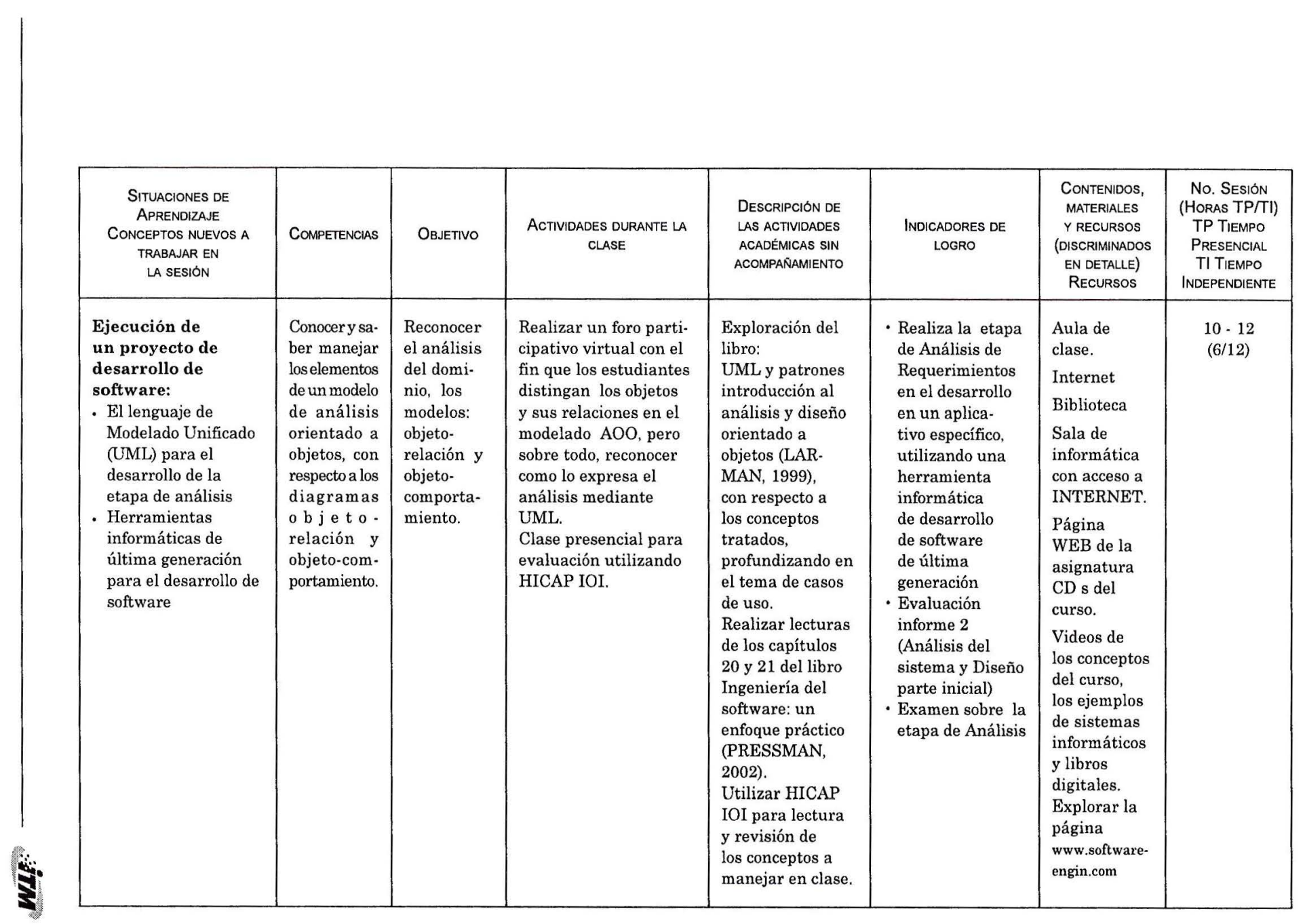




\begin{tabular}{|c|c|c|c|c|c|c|c|}
\hline $\begin{array}{c}\text { SITUACIONES DE } \\
\text { APRENDIZAJE } \\
\text { CONCEPTOS NUEVOS A } \\
\text { TRABAJAR EN } \\
\text { LA SESIÓN }\end{array}$ & COMPETENCIAS & Obuetivo & $\begin{array}{c}\text { ACTIVIDADES DURANTE LA } \\
\text { CLASE }\end{array}$ & $\begin{array}{l}\text { DESCRIPCIÓN DE } \\
\text { LAS ACTIVIDADES } \\
\text { ACADÉMICAS SIN } \\
\text { ACOMPAÑAMIENTO }\end{array}$ & $\begin{array}{l}\text { INDICADORES DE } \\
\text { LOGRO }\end{array}$ & $\begin{array}{l}\text { CONTENIDOS, } \\
\text { MATERIALES } \\
\text { Y RECURSOS } \\
\text { (DISCRIMINADOS } \\
\text { EN DETALLE) } \\
\text { RECURSOS }\end{array}$ & $\begin{array}{c}\text { NO. SESION } \\
\text { (HORAS TP/TI) } \\
\text { TP TIEMPO } \\
\text { PRESENCIAL } \\
\text { TI TIEMPO } \\
\text { INDEPENDIENTE }\end{array}$ \\
\hline $\begin{array}{l}\text { Principios y } \\
\text { conceptos del } \\
\text { diseño } \\
\text { - El lenguaje } \\
\text { de Modelado } \\
\text { Unificado (UML) } \\
\text { para la etapa de } \\
\text { Diseño }\end{array}$ & $\begin{array}{l}\text { Conocer } \\
\text { y saber } \\
\text { manejar } \\
\text { los ele- } \\
\text { mentos de } \\
\text { un modelo } \\
\text { de diseño } \\
\text { orientado } \\
\text { a objetos, } \\
\text { desde su } \\
\text { concepción } \\
\text { Imple- } \\
\text { mentar los } \\
\text { diseños a } \\
\text { un apli- } \\
\text { cativo de } \\
\text { software. }\end{array}$ & $\begin{array}{l}\text { Reconocer } \\
\text { el proceso } \\
\text { del diseño } \\
\text { en general } \\
\text { y del diseñ } \\
\text { orientado } \\
\text { a objetos } \\
\text { en parti- } \\
\text { cular }\end{array}$ & $\begin{array}{l}\text { Retomar los ejemplos } \\
\text { de la bibliografía } \\
\text { con el fin de que los } \\
\text { estudiantes distingan } \\
\text { los elementos del } \\
\text { diseño orientado a } \\
\text { objetos, mediante } \\
\text { UML. } \\
\text { Asesoría al informe } \\
\text { 2, sobre los temas de } \\
\text { diseño. } \\
\text { Evaluación del informe } \\
\text { 2. (Análisis del sistema } \\
\text { y Diseño Parte inicial). }\end{array}$ & $\begin{array}{l}\text { Utilizando el } \\
\text { AOO realizar } \\
\text { la narrativa, } \\
\text { clases, atributos } \\
\text { y métodos, los } \\
\text { casos de uso, } \\
\text { curso normal } \\
\text { de los eventos } \\
\text { utilizando una } \\
\text { herramienta } \\
\text { informática } \\
\text { como Visio, UML } \\
\text { parading etc; } \\
\text { como parte del } \\
\text { informe número } \\
2 \text {. } \\
\text { Análisis del } \\
\text { sistema } 20 \% \text { (En } \\
\text { grupos de } 3 \text { a } 5 \\
\text { estudiantes)-. } \\
\text { Asistir a asesoría } \\
\text { con el docente } \\
\text { en los grupos de } \\
\text { trabajo. } \\
\text { Ingresar el } \\
\text { informe } 1 \text { y lo } \\
\text { que se lleva } \\
\text { del segundo al } \\
\text { aplicativo HICAP } \\
\text { IOI. }\end{array}$ & $\begin{array}{l}\text { Realiza la } \\
\text { etapa de Diseño } \\
\text { de Software en } \\
\text { el desarrollo en } \\
\text { un aplicativo } \\
\text { específico, } \\
\text { utilizando una } \\
\text { herramienta } \\
\text { informática } \\
\text { de desarrollo } \\
\text { de software } \\
\text { de última } \\
\text { generación } \\
\\
\text { Realiza el } \\
\text { desarrollo } \\
\text { completo de } \\
\text { un aplicativo } \\
\text { software en } \\
\text { la solución de } \\
\text { un problema } \\
\text { específico de } \\
\text { un proceso } \\
\text { productivo. }\end{array}$ & $\begin{array}{l}\text { Aula de clase } \\
\text { Internet } \\
\text { Biblioteca } \\
\text { CD s del } \\
\text { curso. } \\
\text { Videos de } \\
\text { los conceptos } \\
\text { del curso, } \\
\text { los ejemplos } \\
\text { de sistemas } \\
\text { informáticos } \\
\text { y libros } \\
\text { digitales. } \\
\text { Explorar la } \\
\text { página } \\
\text { www. } \\
\text { software- } \\
\text { engin.com } \\
\text { Aplicativo } \\
\text { HICAP IOI }\end{array}$ & $\begin{array}{c}13-14 \\
(4 / 8)\end{array}$ \\
\hline
\end{tabular}




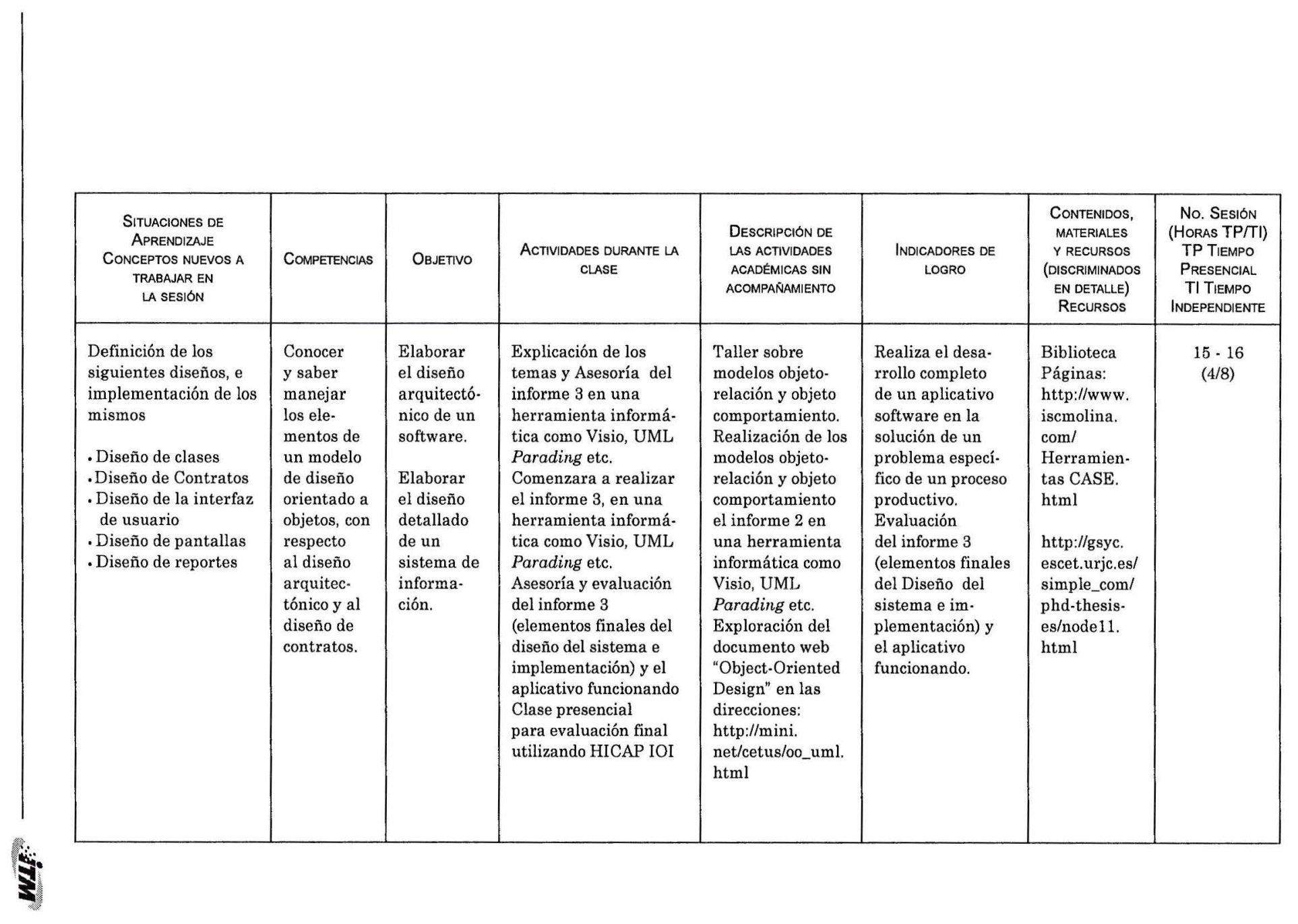




\begin{tabular}{|c|c|c|c|c|c|c|c|}
\hline $\begin{array}{l}\text { SITUACIONES } \\
\text { DE } \\
\text { APRENDIZAJE } \\
\text { CONCEPTOS } \\
\text { NUEVOS A } \\
\text { TRABAJAR EN } \\
\text { LA SESIÓN } \\
\end{array}$ & COMPETENCIAS & OBJEtIVo & $\begin{array}{l}\text { ACTIVI- } \\
\text { DADES } \\
\text { DURANTE } \\
\text { LA CLASE }\end{array}$ & $\begin{array}{l}\text { DESCRIPCIÓN DE LAS ACTIVIDADES } \\
\text { ACADÉMICAS SIN ACOMPANAMIENTO }\end{array}$ & $\begin{array}{l}\text { INDICADORES DE } \\
\text { LOGRO }\end{array}$ & $\begin{array}{l}\text { CONTENIDOS, } \\
\text { MATERIALES } \\
\text { Y RECURSOS } \\
\text { (DISCRIMINADOS } \\
\text { EN DETALLE) } \\
\text { RECURSOS }\end{array}$ & $\begin{array}{c}\text { No. SESIÓN } \\
\text { (HORAS TP/TI) } \\
\text { TP TIEMPO } \\
\text { PRESENCIAL } \\
\text { TI TIEMPO } \\
\text { INDEPENDIENTE }\end{array}$ \\
\hline . & $\begin{array}{l}\text { Imple- } \\
\text { mentar los } \\
\text { diseños a } \\
\text { un apli- } \\
\text { cativo de } \\
\text { software. }\end{array}$ & $\begin{array}{l}\text { Entrega } \\
\text { del } \\
\text { aplicativo } \\
\text { funcionan- } \\
\text { do. }\end{array}$ & & $\begin{array}{l}\text { Utilizar HICAP IOI para lectura } \\
\text { y revisión de los conceptos a } \\
\text { manejar en clase. } \\
\text { Realizar lecturas del capítulos } \\
22,25 \text { y } 26 \text { del libro Ingeniería } \\
\text { del software: un enfoque práctico } \\
\text { (PRESSMAN, 2002). } \\
\text { Realizar lecturas del capítulos } \\
22,25 \text { y } 26 \text { del libro Ingeniería } \\
\text { del software: un enfoque práctico } \\
\text { (PRESSMAN, 2002). } \\
\text { Exploración del libro: } \\
\text { UML y patrones introducción } \\
\text { al análisis y diseño orientado a } \\
\text { objetos (LARMAN, 1999), con } \\
\text { respecto a los conceptos tratados, } \\
\text { enfatizando en contratos. } \\
\text { Asistir a asesoría con el docente } \\
\text { en los grupos de trabajo. } \\
\text { Ingresar el informe } 3 \text { al aplicativo } \\
\text { HICAP IOI. } \\
\text { Desarrollar los ejercicios al final } \\
\text { del capítulo } 22 \text { del libro de PRES. } \\
\text { SMAN, Roger S. Ingeniería del } \\
\text { Software: un enfoque práctico. } 5 \text {. } \\
\text { ed. Madrid McGraw-Hill, 2002. } \\
601 \text { p. }\end{array}$ & $\begin{array}{l}\text { Examen sobre } \\
\text { Diseño } 20 \% \text {. } \\
\text { Terminación del } \\
\text { seguimiento } 10 \%\end{array}$ & $\begin{array}{l}\text { Sala de } \\
\text { informática } \\
\text { con acceso a } \\
\text { INTERNET. }\end{array}$ & \\
\hline
\end{tabular}




\subsection{Bibliografia del curso}

BOOCH, Grady. (1998). Análisis y diseño orientado a objetos con aplicaciones. $2^{a}$ ed. México: s.n. 638 p.

BOOCH, Grady; RUMBAUGH, James; JACOBSON, Ivar. (1999). El lenguaje unificado de modelado. Madrid: Addison Wesley. 432 p. + CD-ROM.

BROPHY, J. (1999) Teaching En UNESCO: Educational Practices Series, $\mathrm{n}^{\circ} 1,35$.

GUERRERO, Diego. (2007). Elementos básicos de ingeniería del software. Medellín: ITM, próximo a editar.

LARMAN, Craig. (1999). UML y patrones introducción al análisis y diseño orientado a objetos. México: Prentice-Hall. 507 p. $2^{\mathrm{a}}$ edición.

MEYER, Bertrand. Construcción de software orientado a objetos. 2. ed. Madrid, Prentice-Hall, 1999. 1198 p. + CD-ROM.

PRESSMAN, Roger S. (2002). Ingeniería del software: un enfoque práctico. 5. ed. Madrid: McGraw-Hill. 601p.

TOPPING, K. (2000) Tutoring En UNESCO: Educational Practices Series $\mathrm{n}^{\circ} 5,35 \mathrm{p}$.

http://www.ibe.unesco.org/International/Publications/EducationalPractices/prachome.htm. Tomado de la red el 25 de septiembre de 2002.

\section{Conclusiones Y TRABAIO futuros}

Este artículo ha presentado una propuesta para la didáctica en la enseñanza de la Ingeniería de Software dirigida hacia la formación de competencias que dinamicen la práctica del desarrollo en las empresas de software. El modelo de enseñanza en el cual se basa se sustenta en teorías pedagógicas que perciben el proceso de aprendizaje en ciclos consecutivos a manera de espiral, fundamentado en la Teoría de la Actividad.

El presente trabajo permitió una conceptualización más próxima de las teorías del aprendizaje y cómo se pueden aplicar en un contexto real de enseñanza y aprendizaje de la Ingeniería del Software.

La experiencia docente no es suficiente por sí misma, se requiere de un recorrido histórico para comprender aún mejor las distintas 
formas como el hombre aprende y las distintas formas como el hombre enseña. Es necesario comprender los diferentes estadios del hombre, del conocimiento y de la tecnología para poder desarrollar estrategias de enseñanza y aprendizaje cada vez más certeras.

No hay duda que las TIC permiten un mayor acercamiento a la información, asimismo, es de gran ayuda tanto para los docentes como para los estudiantes en su proceso de aprendizaje, puesto que en el aula de clase todos aprenden.

Esta propuesta de estrategias didácticas y diseño curricular para el curso básico de la enseñanza de la Ingeniería del Software a partir del proyecto SWEBOK, es el resultado de acciones concretas que se vienen desarrollando en la decanatura de Sistemas de Información, del INSTITUTO TECNOLÓGICO METROPOLITANO - ITM-, en conjunto con la Escuela de Pedagogía de la misma Institución, para fortalecer el perfil del ingeniero de Sistemas de Información, como desarrollador de software.

En la nueva estructura del currículo (2007-1) el área de Ingeniería de Software cuenta con dos asignaturas en los semestres V y VIII dentro del ciclo de formación básica. Los estudiantes que optan por enfatizar en el tema tendrán la oportunidad de seleccionar una electiva que sirve de profundización en algunos temas (ingeniería de requisitos, análisis y diseño orientado a objetos, métricas de software, calidad de software aún no definida oficialmente). Este trabajo permitió una reflexión profunda acerca de la práctica del desarrollo del software, además que abrió un espacio para el análisis de la didáctica que se estaba llevando a cabo en las asignaturas analizadas.

El diseño del currículo fundamentado en las competencias y en las actividades de conocimiento antes que en contenidos temáticos, favorece una tendencia de aprendizaje orientada al quehacer de la práctica del desarrollo en las empresas de software. Esta postura exige que la universidad establezca nexos coherentes con las industrias, conozca sus problemas y proponga mecanismos academia-empresa que favorezcan la participación de los estudiantes en proyectos encaminados a solucionar problemas reales de las 
empresas, partiendo de propuestas y políticas establecidas desde el Centro de Investigación.

Este trabajo continúa con una definición detallada del diseño curricular de la asignatura Ingeniería del Software, donde se detallarán las estrategias de aprendizaje dando prioridad a la didáctica expuesta en este artículo, y donde se debe especificar las ayudas informáticas y virtuales que apoyan de una manera más dinámica este curso. Además es un resultado del proyecto de investigación HICAP-IOI (GUERRERO, 2006a), siendo ésta la base para todas las demás ayudas de informática-educativa que acompañarán al curso en un futuro.

Se requieren plantear las Guías de Trabajo independiente, de manera que incluyan elementos de informática educativa, así como de virtualidad, con el fin de facilitar el aprendizaje en los alumnos.

Continuar desarrollando el Proyecto HICAP-IOI con las nuevas propuestas de ayudas virtuales, interactivas y computacionales y extenderlas a otras asignaturas.

\section{RefEREnCIAS}

ANAYA, Raquel (2005). Una visión de la enseñanza de la ingeniería de software como apoyo a las empresas de software. Medellín: Revista Universidad EAFIT. Próximo a publicar.

ANAYA, Raquel y TRUJILLO, John. (2006),"Un modelo para la enseñanza en contexto de la Ingeniería del Software". Medellín: Departamento de Informática y Sistemas de la Universidad E.A.F.I.T.

BOOCH, Grady(1998). Análisis y diseño orientado a objetos con aplicaciones. $2^{\text {a }}$ ed. México: s.n., 638 p.

BOOCH, Grady; RUMBAUGH, James; JACOBSON, Ivar (1999). El lenguaje unificado de modelado. Madrid: Addison Wesley. 432 p. + CD-ROM.

BROPHY, J. (1999).Teaching en UNESCO: Educational practices series, $\mathrm{N}^{\circ} 1,35$.

$<$ http://www.ibe.unesco.org/International/Publications/EducationalPractices/prachome.htm $>$ tomado de la red el 25 de septiembre de 2002 . 
COLON, A. J. (2002).La (de) construcción del conocimiento pedagógico: Nuevas perspectivas en la Teoría de la educación ". Barcelona: Ediciones Paidos, (Pág. 83-157).

GUERRERO, Diego. (2006), Diseño del micro currículo "Ingeniería del software ISI54". Medellín: Decanatura Ingeniería de sistemas de información, Instituto Tecnológico Metropolitano. Disponible en www.itm. edu.co

A. (2006A) Herramienta informática como apoyo pedagógico a la asignatura ingeniería del software orientado a objetos -HICAP-IOIProyecto de investigación. Medellín: Centro de investigación Instituto Tecnológico Metropolitano.

B. (2006B). Guías de trabajo independiente del núcleo: "ingeniería del software orientado a objetos IOI52". Medellín: Decanatura Ingeniería de sistemas de información, Instituto Tecnológico Metropolitano, Guide to the Software Engineering Body of Knowledge. SWEBOK,2004 Version. A project of the IEEE Computer Society Professional Practices Comité. Disponible en www.swebok.org

LARMAN, Craig. (1999). UML y patrones introducción al análisis y diseño orientado a objetos. $2^{\mathrm{a}}$ edición. México: Prentice-Hall. 507p.

LEONTIEV, A. N. (1981). Problems of the development of the mind. Moscow: Editorial Progress.

MEYER, Bertrand. (1999) Construcción de software orientado a objetos. $2^{\mathrm{a}}$ ed. Madrid: Prentice-Hall, 1198 p. + CD-ROM.

POZO, J.I. (1989) “Teorías cognitivas del aprendizaje”. Madrid: Ed. Morata.

PRESSMAN, Roger S. (2002). Ingeniería del software: un enfoque práctico. 5. ed. Madrid: McGraw-Hill. 601p.

PROGRAMA ACADÉMICO INGENIERIA DE SISTEMAS DE INFORMACIÓN DEL ITM 2007. (2007). Plan de estudios. Medellín: Decanatura Ingeniería de sistemas de información, Instituto Tecnológico Metropolitano. Disponible en www.itm.edu.co

TOPPING, K. (2000). Tutoring En UNESCO: Educational Practices Series $\mathrm{n}^{\circ} 5,35$.

TRUJLLO V, John Antonio y JARAMILLO R., Carlos Mario. (2006). "Estrategias didácticas en educación superior con la mediación de la computación móvil", Revista Educación y Pedagogía, Medellín, Universidad de Antioquia, facultad de Educación, vol. XVIII, num. 45, (Mayo-agosto). 93-107p. 
URREGO, María Idilia; CASTAÑO, Luz Elena. (1999).Modelo pedagógico. Medellín: Instituto Tecnológico Metropolitano,

VYGOTSKI, L. S. (1996). El desarrollo de los procesos psicológicos superiores. Barcelona: Crítica traducción de "Mind in Society. The development of Higher Psychological Processes" Cambridge, Massachusetts: Harvard University Press,.

$<$ http://www.ibe.unesco.org/International/Publications/Educational Practices/prachome.htm $>$ tomado de la red el 25 de septiembre de 2002 .

\section{Agradecimientos}

Mis más sinceros agradecimientos a la doctora Idilia Urrego del ITM por su colaboración y desinteresado apoyo en la pertinencia pedagógica del trabajo; igualmente, a la doctora Raquel Anaya y al doctor John Trujillo de la Universidad EAFIT, por sus conocimientos y enseñanzas, y sobre todo por su confianza, que permitieron la elaboración de este artículo.

Agradezco, en gran manera, al ingeniero Fray Osorio, Decano de Ingeniería de Sistemas de Información del ITM por su colaboración y confianza, al docente Alejandro Villa y alumnos de las asignatura "Ingeniería del Software Orientada a Objetos IOI52" 2007 del ITM, que me ayudaron en la revisión y actualización de este trabajo, a los integrantes del proyecto HICAP IOI por su trabajo investigativo. 
